\title{
ChemComm
}

\section{Terbium(III)-cholate functionalized vesicles as luminescent indicators for the enzymatic \\ conversion of dihydroxynaphthalene diesters $\dagger$}

Cite this: Chem. Commun., 2014, 50,7852

Received 15th May 2014

Accepted 3rd June 2014

DOI: $10.1039 / c 4 c c 03724 c$

www.rsc.org/chemcomm

\author{
Stefan Balk, ${ }^{a}$ Uday Maitra*b and Burkhard König* ${ }^{{ }^{a}}$
}

The phosphorescence intensity of unilamellar DOPC vesicles with embedded $\mathrm{Tb}^{3+}$-cholate complexes depends on the concentration of dihydroxynaphthalene (DHN) as sensitizer in solution. This was used to monitor the enzymatic conversion of DHN esters or DHN glucosides by enzymes in aqueous buffered solution.

Cholic acids are known to aggregate in the presence of trivalent lanthanide ions resulting in three dimensional networks of hydrogels. ${ }^{1}$ Such gels have found applications as optical materials, ${ }^{1 a, b, 2}$ in the preparation of nanoparticles, ${ }^{1 c, 3}$ as confined reaction media ${ }^{4}$ and in the detection of analytes. ${ }^{5}$ The lanthanide luminescence of hydrogels prepared from sodium cholate and terbium(III) salt is sensitized by 2,3-dihydroxynaphthalene (DHN). Only the dihydroxy compound coordinates to the $\mathrm{Tb}^{3+}$ ion and acts as sensitizer, but not DHN ester or acetal derivatives. ${ }^{1 a}$ This observation has been used to monitor the enzymatic conversion of carboxy esters or the monoglucoside of DHN by changes in the phosphorescence intensity avoiding interference with background fluorescence. ${ }^{6,7}$ The luminescent gel indicator is readily prepared by self-assembly of all components in aqueous buffer, but the three dimensional gel limits the diffusion and the enzymes have to be added during gel preparation. Therefore we transferred this detection mechanism from hydrogels to the membrane of small unilamellar vesicles (Scheme 1). Functionalized lipid bilayers have been previously used in enzyme assays ${ }^{8}$ or as luminescent indicators. ${ }^{9}$

A vesicular solution of 1,2-dioleoyl-sn-glycero-3-phosphatidylcholine (DOPC, $5 \mathrm{mM}$ ) in HEPES buffer ( $25 \mathrm{mM}$, pH 7.4), was prepared by extrusion in the presence of a submicellar concentration $\ddagger$ of cholic acid ( $0.75 \mathrm{mM})$. The cholic acid will phase separate in the DOPC membrane and added $\mathrm{TbCl}_{3} \cdot 6 \mathrm{H}_{2} \mathrm{O}(0.25 \mathrm{mM})$ coordinates to the membrane embedded bile salts. Alternatively, a post

\footnotetext{
${ }^{a}$ Faculty of Chemistry and Pharmacy, University of Regensburg, 93040 Regensburg, Germany. E-mail: burkhard.koenig@ur.de; Fax: +49 943 1717; Tel: +499434576

${ }^{b}$ Department of Organic Chemistry, Indian Institute of Science, Bangalore, India.

E-mail: maitra@orgchem.iisc.ernet.in; Fax: +91-80-2360-0529;

Tel: +91-80-2360-1968

$\dagger$ Electronic supplementary information (ESI) available. See DOI: 10.1039/c4cc03724c
}

functionalization of DOPC vesicles by bile salts and $\mathrm{Tb}(\mathrm{III})$ is possible, when the components are added to buffered DOPC vesicle solutions. We assume the formation of membrane anchored terbium(III)-complex domains. The resulting vesicle solutions are homogeneous, stable and monodisperse.

Next, DHN $(12.5 \mu \mathrm{M})$ was added to the aqueous vesicle solution Vs1 $\left(C_{(\mathrm{DOPC})}=5 \mathrm{mM}, C_{(\mathrm{Chol})}=0.75 \mathrm{mM}\right)$. Excitation of the mixture at $335 \mathrm{~nm}$ gave a significant terbium luminescence with an emission maximum at $545 \mathrm{~nm}$ (Scheme 2). Previous studies have shown that the DHN sensitization of the lanthanide emission requires a rigid gel matrix. ${ }^{1 a, 5 a}$ The strong increase of terbium luminescence in the vesicle membrane therefore indicates that the $\mathrm{Tb}^{3+}$-cholate patches might have gel like properties.

The presence of cholic acid, DHN and terbium(III) salts as membrane additives is essential to observe the lanthanide emission (Scheme 2), which was confirmed by different DOPC vesicle solutions (Vs2: $C_{(\mathrm{DOPC})}=5 \mathrm{mM}, \mathrm{Vs} 1: C_{(\mathrm{DOPC})}=5 \mathrm{mM}$, $C_{(\mathrm{Chol})}=0.75 \mathrm{mM}$, Vs3: $C_{(\mathrm{DOPC})}=5 \mathrm{mM}, C_{(\mathrm{Chol})}=0.75 \mathrm{mM}$, $\left.C_{\left(\mathrm{Tb}^{3+}\right)}=0.25 \mathrm{mM}, C_{(\mathrm{DHN})}=12.5 \mu \mathrm{M}\right)$ and post functionalized DOPC vesicles (Vs3p: $C_{(\mathrm{DOPC})}=5 \mathrm{mM}, C_{(\mathrm{Chol})}=0.75 \mathrm{mM}, C_{\left(\mathrm{Tb}^{3+}\right)}=0.25 \mathrm{mM}$, $\left.C_{(\mathrm{DHN})}=12.5 \mu \mathrm{M}\right)$. Dynamic light scattering (DLS) confirmed a monodisperse narrow size distribution around $110 \mathrm{~nm}$ for all samples. In contrast, solutions of cholate monomers $(0.75 \mathrm{mM})$ in HEPES buffer ( $25 \mathrm{mM}$, pH 7.4) or $\mathrm{CHCl}_{3}$ showed a broad size distribution and polydispersity (see ESI $\dagger$ for data). The embedding of the luminescent cholic acid-terbium complexes in the vesicle membrane was confirmed by fluorescence anisotropy: the terbium complex, excited by DHN $(12.5 \mu \mathrm{M})$ at $335 \mathrm{~nm}$, and bound to cholic acid doped vesicles Vs4 $\left(C_{(\mathrm{DOPC})}=5 \mathrm{mM}, C_{(\mathrm{Chol})}=0.75 \mathrm{mM}\right.$, $\left.C_{\left(\mathrm{Tb}^{3+}\right)}=0.25 \mathrm{mM}\right)$ showed a fluorescence anisotropy, detected at $550 \mathrm{~nm}$, which is about 8 times higher than for terbium in aqueous cholic acid solution $\left(C_{(\mathrm{Chol})}=0.75 \mathrm{mM}, C_{\left(\mathrm{Tb}^{3+}\right)}=0.25 \mathrm{mM}\right.$, $\left.C_{(\mathrm{DHN})}=12.5 \mu \mathrm{M}\right)$. Higher anisotropy values detected at $380 \mathrm{~nm}$ of DHN $(12.5 \mu \mathrm{M})$ in the presence of Vs4 compared to aqueous cholate solution indicated the coordination of DHN to terbium(III) ions at the surface of vesicle Vs4 (see ESI $\dagger$ for data).

Since DHN derivatives lacking free hydroxy groups for metal coordination, do not sensitize the terbium(III) emission, 


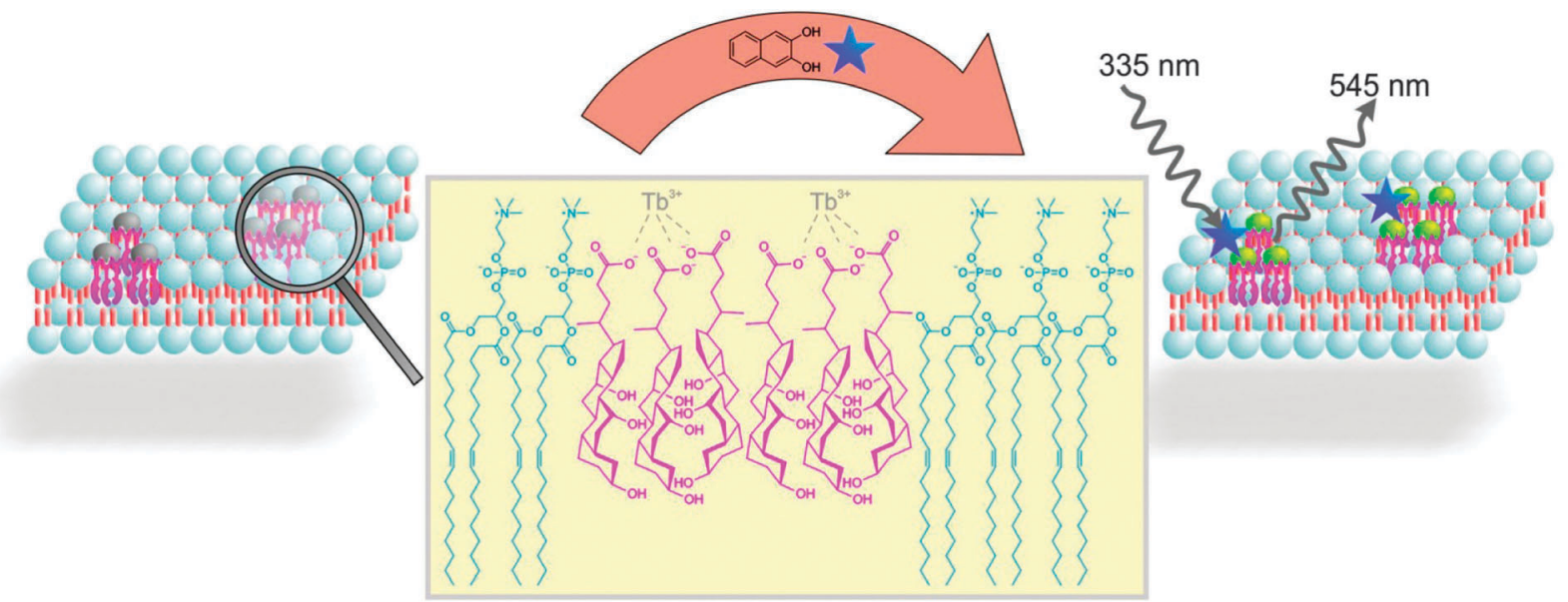

Scheme 1 Self assembly of amphiphiles (DOPC) and cholates in aqueous solution yields gel-functionalized small unilamellar vesicles after extrusion. The addition of dihydroxynaphthalene (DHN), which is coordinating to the metal complex, sensitizes the $\mathrm{Tb}^{3+}$-luminescence.

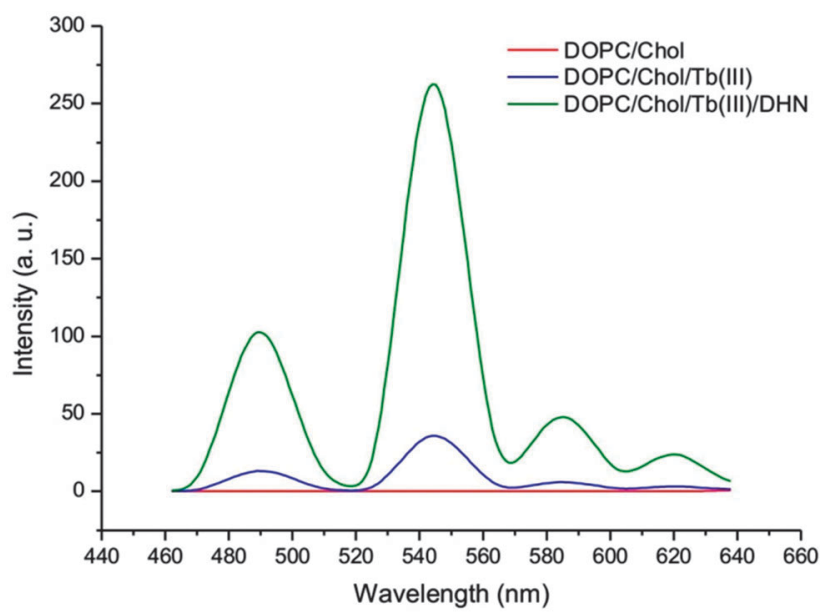

Scheme 2 Excitation of DHN at $335 \mathrm{~nm}$ in a cholate doped vesicle solution results in a strong $\mathrm{Tb}^{3+}$-phosphorescence emission (green); without sensitizer (blue) the terbium luminescence is weak; no emission is detected for cholatevesicles (red).

reactions converting DHN derivatives into DHN can be easily monitored by the functionalized vesicles. Lipase (Candida rugosa, $\left.2.5 \mathrm{U} \mathrm{mg}^{-1}, 50 \mathrm{mg} \mathrm{L}^{-1}\right)$ was added to the aqueous vesicle solution Vs1 $\left(C_{(\mathrm{DOPC})}=5 \mathrm{mM}, C_{(\mathrm{Chol})}=0.75 \mathrm{mM}\right)$ with added $\mathrm{TbCl}_{3} \cdot 6 \mathrm{H}_{2} \mathrm{O}$ $(0.25 \mathrm{mM})$ and naphthalene-2,3,-diyl dihexanoate (DHNdhn, $12.5 \mu \mathrm{M}$ ) or naphthalene-2,3-diyl diacetate (DHNdac). The enzymatic ester cleavage of DHNdhn into DHN leads to an increase of the vesicle luminescence intensity tracing the reaction (Schemes 3 and 4). 3-Hydroxynaphthalene-2-yl- $\beta$-glucoside (DHNglu) was likewise used to monitor the enzymatic activity of $\beta$-glucosidase (from almonds, $6.5 \mathrm{U} \mathrm{mg}^{-1}, 50 \mathrm{mg} \mathrm{L}^{-1}$ ).

To confirm that the emission intensity change during the reaction correlates with the amount of produced DHN, we monitored the enzymatic conversion by HPLC in the absence of vesicles. The initial rate constants for the esterase activity of lipase derived from the emission intensity increase or the HPLC analysis of produced DHN were comparable with $1.3 \times 10^{-8}$ and $1.9 \times 10^{-8} \mathrm{mmol} \mathrm{min}^{-1}$, respectively, (see ESI† for data).§ A detection limit of $0.5 \mathrm{mg} \mathrm{L}^{-1}$ for

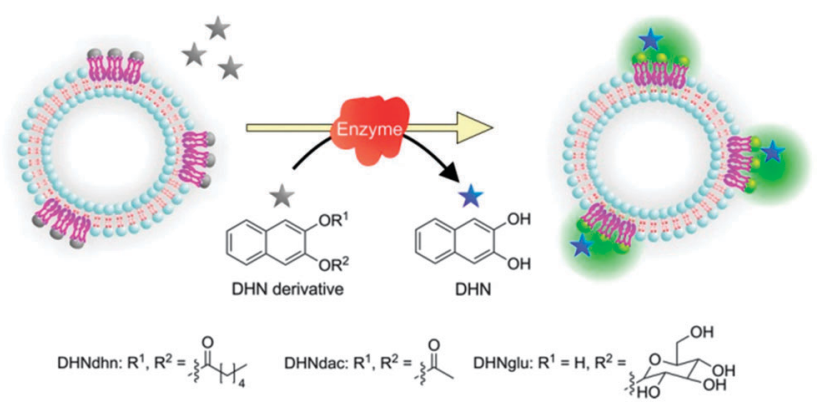

Scheme 3 Lipase conversion of naphthalene-2,3-dihydroxyesters (12.5 $\mu \mathrm{M})$ into DHN leads to an increase of the terbium luminescence intensity.

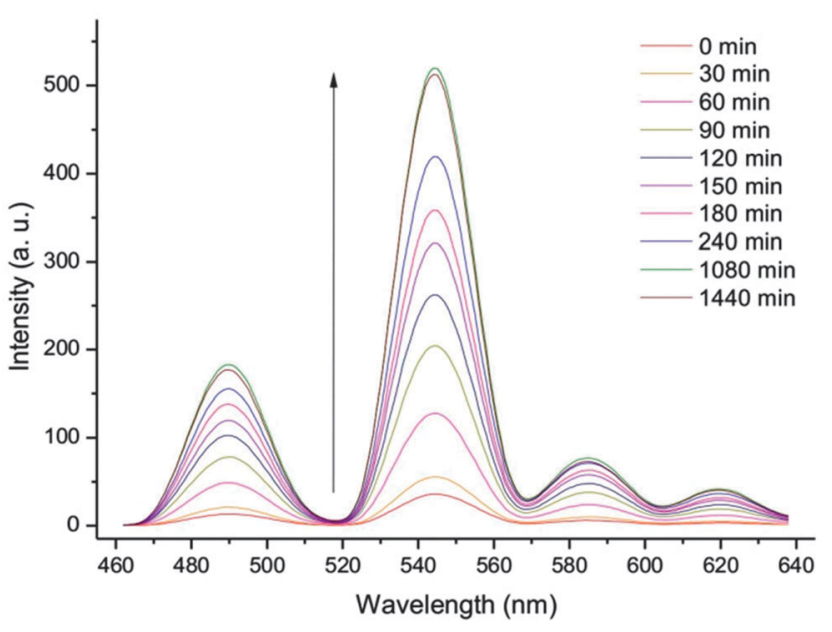

Scheme 4 Luminescence intensity of Vs4 $\left(C_{(\mathrm{DOPC})}=5 \mathrm{mM}, C_{(\text {Chol })}=0.75 \mathrm{mM}\right.$, $\left.C_{\left(\mathrm{Tb}^{3+}\right)}=0.25 \mathrm{mM}\right)$ is increasing in the presence of DHNdhn $(12.5 \mu \mathrm{M})$ and lipase (50 $\mathrm{mg} \mathrm{L}^{-1}$ ) over $24 \mathrm{~h}$.

lipase activity was determined for the assay using a $24 \mathrm{~h}$ incubation time, which significantly improved compared to the previously used hydrogels that required $900 \mathrm{mg} \mathrm{L}^{-1.5 a}$

In conclusion, we have embedded terbium-cholate aggregates into the membrane of $100 \mathrm{~nm}$ unilamellar DOPC vesicles. 
Dihydroxynaphthalene coordinates to the complexes at the membrane-water interface and sensitizes the terbium phosphorescence. As the concentration of free dihydroxynaphthalene in the aqueous solution correlates with the terbium phosphorescence intensity, enzymatic reactions of dihydroxynaphthalene esters and glycosides can be monitored in buffered aqueous solution. The phosphorescent vesicular indicator is easily prepared by selfassembly and many DHN derivatives as pro-sensitizers can be envisaged that are suitable substrates for a variety of enzymes. The detection principle may therefore find application as a facile luminescent on-line monitoring of enzymatic activity.

SB thanks the INDIGO network of the German Academic Exchange Service (DAAD) for travel support.

\section{Notes and references}

\$ Critical micellar concentration (cmc) for sodium cholate is $9-14 \mathrm{mM}$. $\S$ Non-enzymatic spontaneous hydrolysis of DHN esters over $24 \mathrm{~h}$ is negligible.

1 (a) S. Banerjee, R. Kandanelli, S. Bhowmik and U. Maitra, Soft Matter, 2011, 7, 8207-8215; (b) S. Bhowmik, S. Banerjee and U. Maitra, Chem. Commun., 2010, 46, 8642-8644; (c) A. Chakrabarty, U. Maitra and A. D. Das, J. Mater. Chem., 2012, 22, 18268-18274; (d) H. Svobodová, V. Noponen, E. Kolehmainen and E. Sievänen, RSC Adv., 2012, 2, 4985-5007; (e) For an X-ray structure analysis of lanthanide - DHN complex, see: D. I. Alexandropoulos, A. Fournet, L. Cunha-Silva, A. M. Mowson, V. Bekiari, G. Christou and T. C. Stamatatos, Inorg. Chem., 2014, DOI: 10.1021/ic500806n.
2 (a) Y. Qiao, Y. Lin, S. Zhang and J. Huang, Chem. - Eur. J., 2011, 17, 5180-5187; (b) X. Ma, D. Yu, N. Tang and J. Wu, Dalton Trans., 2014, DOI: $10.1039 /$ c4dt00110a.

3 Y. Qiao, H. Chen, Y. Lin, Z. Yang, X. Cheng and J. Huang, J. Phys. Chem. C, 2011, 115, 7323-7330.

4 (a) S. Bhat and U. Maitra, Molecules, 2007, 12, 2181-2189; (b) J. Bachl, A. Hohenleutner, B. B. Dhar, C. Cativiela, U. Maitra, B. Konig and D. D. Diaz, J. Mater. Chem. A, 2013, 1, 4577-4588.

5 (a) S. Bhowmik and U. Maitra, Chem. Commun., 2012, 48, 4624-4626; (b) S. Mizukami, K. Tonai, M. Kaneko and K. Kikuchi, J. Am. Chem. Soc., 2008, 130, 14376-14377; (c) T. Terai, K. Kikuchi, Y. Urano, H. Kojima and T. Nagano, Chem. Commun., 2012, 48, 2234-2236; (d) T. Terai, H. Ito, K. Kikuchi and T. Nagano, Chem. - Eur. J., 2012, 18, 7377-7381.

6 (a) T. Steinkamp, F. Schweppe, B. Krebs and U. Karst, Analyst, 2003, 128, 29-31; (b) K.-H. Leung, H.-Z. He, V. P.-Y. Ma, H.-J. Zhong, D. S.-H. Chan, J. Zhou, J.-L. Mergny, C.-H. Leung and D.-L. Ma, Chem. Commun., 2013, 49, 5630-5632; (c) B. K. McMahon and T. Gunnlaugsson, J. Am. Chem. Soc., 2012, 134, 10725-10728; (d) U. Reddy G, P. Das, S. Saha, M. Baidya, S. K. Ghosh and A. Das, Chem. Commun., 2013, 49, 255-257; (e) J. Hu, G. Zhang and S. Liu, Chem. Soc. Rev., 2012, 41, 5933-5949.

7 Reviews on lanthanide probes for the determination of enzymatic activity, see: (a) C. M. Spangler, C. Spangler and M. Schäerling, Ann. N. Y. Acad. Sci., 2008, 1130, 138-148; (b) E. F. Gudgin Dickson, A. Pollak and E. P. Diamandis, J. Photochem. Photobiol., B, 1995, 27, 3-19; (c) R. A. Evangelista, A. Pollak and E. F. Gudgin Templeton, Anal. Biochem., 1991, 197, 213-224.

8 (a) G. Das, P. Talukdar and S. Matile, Science, 2002, 298, 1600-1602; (b) T. Takeuchi and S. Matile, Chem. Commun., 2013, 49, 19-29; (c) P. Walde and S. Ichikawa, Biomol. Eng., 2001, 18, 143-177.

9 (a) B. Gruber and B. König, Chem. - Eur. J., 2013, 19, 438-448; (b) B. Gruber, S. Balk, S. Stadlbauer and B. König, Angew. Chem., Int. Ed., 2012, 51, 10060-10063; (c) S. Banerjee and B. König, J. Am. Chem. Soc., 2013, 135, 2967-2970; (d) B. Gruber, S. Stadlbauer, A. Späth, S. Weiss, M. Kalinina and B. König, Angew. Chem., Int. Ed., 2010, 49, 7125-7128. 